\title{
In situ X-ray absorption spectroscopy study of zinc and cadmium transport by S-rich fluids
}

\author{
Elena F. Bazarkina ${ }^{1,2, *}$, Olivier Proux ${ }^{3}$, Eric Lahera ${ }^{3}$, William Del Net $^{3}$, and Jean-Louis \\ Hazemann ${ }^{1}$ \\ ${ }^{1}$ Institut Néel, UPR 2940 CNRS - Université Grenoble Alpes, F-38000 Grenoble, France \\ ${ }^{2}$ IGEM RAS, 119017 Moscow, Russia \\ ${ }^{3}$ OSUG (OSUG), UMS 832 CNRS, Université Grenoble Alpes, F-38041 Grenoble, France
}

\begin{abstract}
This experimental and theoretical study is aimed at better quantifying the transport of $\mathrm{Zn}$ and $\mathrm{Cd}$ by hydrothermal fluids rich in sulfur by using in-situ X-ray absorption spectroscopy (XAS). We measured simultaneously fluorescence and transmission spectra of dissolved metal in $\mathrm{NaHS}-\mathrm{H}_{2} \mathrm{~S}, \mathrm{~K}_{2} \mathrm{~S}_{2} \mathrm{O}_{3}, \mathrm{Na}_{2} \mathrm{~S}_{2} \mathrm{O}_{3}, \mathrm{~K}_{2} \mathrm{~S}_{2} \mathrm{O}_{3}-\mathrm{HCl}$ aqueous solutions at 250$350^{\circ} \mathrm{C}$ and 600 bar. Here the first experimental results are presented. Possible sulfur speciation models for $\mathrm{Zn}$ and $\mathrm{Cd}$ are briefly discussed.
\end{abstract}

\section{Introduction}

Zinc $(\mathrm{Zn})$ and cadmium $(\mathrm{Cd})$ are chalcophile elements, i.e. they have a low affinity for oxygen and prefer to bind with reduced sulfur (i.e. sulfides). Being highly dispersed in the crust, $\mathrm{Zn}$ and $\mathrm{Cd}$ are typically concentrated in hydrothermal sulfide ores. They are common in many types of hydrothermal ore deposits from porphyry to epithermal. These ores are formed by hot $\left(100-600^{\circ} \mathrm{C}\right)$ aqueous solutions, in which sulfur is ubiquitous. At such conditions, sulfur can be an important complexing ligand, competitive with chloride. Numerous studies were devoted to chloride complexes of zinc and cadmium [1-8]. However, to date, comparatively little attention has been paid to the identity, structure and stability of S-bearing complexes [8-9]. The goal of this study is to characterise these species in situ by X-ray absorption spectroscopy (XAS) at high temperature and pressure (T-P). This technique allows to measure both solubility and the local atomic environments of dissolved metal. These data are essential to quantify the role of sulfur in zinc and cadmium transport and precipitation in natural geological hydrothermal systems.

\section{Methods}

Fluorescence and transmission XAS spectra were collected at the Zn K-edge $(9.66 \mathrm{keV})$ over the energy range $9.5-10.5 \mathrm{keV}$ and at the Cd K-edge $(26.71 \mathrm{keV})$ over the energy range $26.5-27.5 \mathrm{keV}$ on BM30b beamline at the European Synchrotron Radiation Facility (ESRF, Grenoble, France). The beam energy was selected using a $\mathrm{Si}(220)$ double-crystal

\footnotetext{
*Corresponding author: elena.f.bazarkina@gmail.com
} 
monochromator. The energy was calibrated using zinc and cadmium metal foils; the K-edge positions were set at $9.659 \mathrm{keV}(\mathrm{Zn})$ and at $26.711 \mathrm{keV}(\mathrm{Cd})$ as the maximum of the first derivative of the main-edge spectrum. The beam size was $300 \mu \mathrm{m}$ horizontal and $200 \mu \mathrm{m}$ vertical (for $\mathrm{Zn}$ ) and $300 \mu \mathrm{m}$ horizontal and $1000 \mu \mathrm{m}$ vertical (for Cd). Transmission spectra were recorded using silicon diodes collecting scattered radiation from a Kapton foil placed in the incidental and transmitted X-ray beam. Fluorescence spectra were collected in the 90 geometry using a Canberra solid-state 30-element germanium detector. Acquisition time for each XAS scan was $40 \mathrm{~min}$. All experiments with aqueous solutions were carried out in a glassy carbon cell placed in autoclave equipped with internal heating system and gas pressure regulation [10]. For solubility experiments, $\mathrm{ZnS}(\mathrm{s})$ and $\mathrm{CdS}(\mathrm{s})$ monocrystals were placed at the cell bottom, and the cell vertical position was optimized such that the solid phases were out of the beam passage through the solution. Thus in-situ spectra of dissolved metals are recorded without signal of solids. Two type of S-bearing solutions were used: thiosulfate ( $\mathrm{S}^{\mathrm{II}+}$ at ambient T-P and $\mathrm{S}^{\mathrm{VI}+}-\mathrm{S}^{\mathrm{II}-}$ at high T-P) and hydrosufide ( $\mathrm{S}^{\mathrm{II}-}$ at all T-P). Despite the fact that reduced $\mathrm{S}$ is expected to bond to dissolved $\mathrm{Zn}$ and $\mathrm{Cd}$, more oxidized conditions allow to increase easily total $\mathrm{S}$ concentration and to approach common geological redox conditions, i.e. sulfate-sulfide equilibrium. Experimental T-P conditions are representative for natural hydrothermal systems at $\sim 6 \mathrm{~km}$ of depth, fluid density is $\geq$ $0.7 \mathrm{~g} \mathrm{~cm}^{-3}$., i.e. at $250-350^{\circ} \mathrm{C}$ and 600 bar. The solubility of sulfides in such fluids are high enough to record high-quality fluorescence XANES and EXAFS spectra and to measure solubility from the transmission spectra (see below) by using hydrothermal optical setup described above. The spectra were recorded at constant pressure (600 bar) and different temperatures $\left(250,300,350^{\circ} \mathrm{C}\right)$. The reference compounds used for comparison include $\mathrm{Zn}$ and $\mathrm{Cd}$ solids containing $\mathrm{O}, \mathrm{Cl}, \mathrm{S}$ and $\mathrm{Zn}$ - and Cd-bearing aqueous solutions where ions $\mathrm{Me}\left(\mathrm{H}_{2} \mathrm{O}\right)_{6}{ }^{2+}$ or chloride complexes $\mathrm{MeCl}_{\mathrm{n}}\left(\mathrm{H}_{2} \mathrm{O}\right)_{4-\mathrm{n}}{ }^{2-\mathrm{n}}(\mathrm{n}=2-4)$ predominate.

Dissolved $\mathrm{Zn}$ and $\mathrm{Cd}$ concentrations in aqueous solutions were determined using the following equation based on the $\mathrm{X}$-ray absorption relation:

$$
\operatorname{mol}_{M e}=\Delta \mu_{t r} /\left(\Delta \delta_{M e} \times M_{M e} \times l \times \rho\right)
$$

where $\operatorname{mol}_{M e}$ is the metal aqueous concentration (moles per $\mathrm{kg}$ of fluid), $\Delta \mu_{t r}$ is the amplitude of the absorption edge height of transmission spectra, $\Delta \delta_{M e}$ is the change of the total absorption cross-section of metal over its K-edge $\left(217.749 \mathrm{~cm}^{2} / \mathrm{g}\right.$ for $\mathrm{Zn}$ and 41.356 $\mathrm{cm}^{2} / \mathrm{g}$ for $\left.\mathrm{Cd}\right), l$ is the optical path length inside the cell $(0.50 \mathrm{~cm}), M_{M e}$ is the metal atomic weight $(0.0654 \mathrm{~kg} / \mathrm{mole}$ for $\mathrm{Zn}$ and $0.1124 \mathrm{~kg} /$ mole for $\mathrm{Cd})$, and $\rho$ is the density of the aqueous solution $\left(\mathrm{g} / \mathrm{cm}^{3}\right)$ at given $\mathrm{T}$ and $\mathrm{P}$.

\section{Results and discussion}

Aqueous solutions rich in reduced sulfur is difficult to prepare at ambient T-P. Aqueous thiosulfate solutions can be used as a source of reduced sulfur at high T-P [11]. To determine $\mathrm{Zn}$ and $\mathrm{Cd}$ speciation in S-rich solutions we recorded XAS spectra of thiosulfate solutions in equilibrium with sphalerite $\mathrm{ZnS}(\mathrm{s})$ and greenockite $\mathrm{CdS}(\mathrm{s})$ at temperatures 250$350^{\circ} \mathrm{C}$ and 600 bar. Solubility of both sphalerite and greenockite attain up to $10^{-3}$ mol per $\mathrm{kg}$ of fluid level at high sulfur concentrations ( $3 \mathrm{~mol}$ of $\mathrm{S}$ per $\mathrm{kg}$ of fluid) as determined from transmission spectra. We have found also that with increasing sulfur concentration, $\mathrm{ZnS}$ and CdS solubility increases. However, due to high total absorption of such S-rich aqueous fluids, the transmission spectra are too noisy and do not provide more accurate spectroscopic information. The fluorescence spectra obtained simultaneously are more appropriate. The experimental fluorescence XANES spectra of $\mathrm{Cd}$ and $\mathrm{Zn}$ complexes in S- 
rich and S-free hydrothermal solutions at high T-P obtained in this study are presented in Figure 1. The spectra of hydrated ions are given at lower temperature because they are unstable at higher $\mathrm{T}$, i.e. $\mathrm{Zn}$ and $\mathrm{Cd}$ were lost from solutions and precipitated at the cell bottom as determined from both fluorescence and transmission spectra. The shape and energy position of the XANES features presented in the Figure 1 are very different between spectra of octahedral ions, tetrahedral chloride complexes and S-bearing species with unknown structure. The latter means strong structural difference among these three type of species. This difference may concern structure (for example, octahedral, tetrahedral, square planar) and interatomic distances.

Comparative analysis of XANES spectra of metal solids with known structure and containing $\mathrm{O}, \mathrm{Cl}$ or $\mathrm{S}$ at ambient T-P (Figure 2) demonstrates that: 1) octahedral coordination (6 oxygen atoms in the first atomic shell) implies the highest first peak in XANES spectrum and the white line shift to higher energy comparing to tetrahedral coordination ( 4 chlorine or 4 sulfur atoms); 2) in the case of $\mathrm{Zn}$, tetrahedral coordination in $\mathrm{ZnCl}_{2}$ (s) is characterized by the shift of the white line to lower energy if comparing with tetrahedral coordination in $\mathrm{ZnS}(\mathrm{s})$. Similarly, in aqueous solutions, octahedral ions have the strongest white line (in the case of $\mathrm{Cd}$ ) and are shifted to higher energies (in the case of $\mathrm{Zn}$ ) if comparing with chloride complexes (Figure 1). Thus, by analogy, we expect that Sbearing aqueous complexes have tetrahedral-like structure. This can be also confirmed by theoretical XANES calculations (in progress).

The results from EXAFS modelling confirms these observations. In S-rich solutions at $300-350^{\circ} \mathrm{C}$, both $\mathrm{Zn}$ and $\mathrm{Cd}$ are surrounded by $3.5 \pm 0.5 \mathrm{~S}$ atoms at $2.33 \pm 0.01 \AA$ (for $\mathrm{Zn}$ ) and at $2.50 \pm 0.01 \AA$ (for $\mathrm{Cd}$ ). These distances are longer than those measured in hydrated ions $(2.07 \pm 0.02 \AA$ for $\mathrm{Zn}-\mathrm{O}, 2.29 \pm 0.02 \AA$ for $\mathrm{Cd}-\mathrm{O})$ and chloride complexes $(2.27 \pm 0.03 \AA$ for $\mathrm{Zn}$ $\mathrm{Cl}, 2.44 \pm 0.03 \AA$ for $\mathrm{Cd}-\mathrm{Cl}$ ). No second shell is detected.

The interpretation of XANES and EXAFS data and development of final speciation model are not trivial. The main difficulties are poorly known sulfur chemistry at high T-P and high $\mathrm{S}$ concentration. At $\mathrm{T}$ above $200^{\circ} \mathrm{C}$, the thiosulfate becomes unstable and decomposes to $\mathrm{SO}_{4}{ }^{2-}, \mathrm{H}_{2} \mathrm{~S}^{0}(\mathrm{aq}) / \mathrm{HS}^{-}$and other intermediate-valence $\mathrm{S}$ species such as $\mathrm{S}_{3}{ }^{-}$ [11]. In our studied solutions, no $\mathrm{O}$ atoms were detected in the S-bearing complexes observed in this study. Thus, sulfate is not bounded to $\mathrm{Zn}$ or $\mathrm{Cd}$. Due to the fact that hydrosulfide $\mathrm{HS}^{-}$and $\mathrm{S}_{3}{ }^{-}$are the major reduced $\mathrm{S}$ species in such solution at $350^{\circ} \mathrm{C}$, the question is open to assign these species to hydrosulfide complexes such as trigonal $\mathrm{Me}(\mathrm{HS})_{3}{ }^{-}$, tetrahedral $\mathrm{Me}(\mathrm{HS})_{4}{ }^{2}-$ or $\mathrm{Me}(\mathrm{HS})_{3}\left(\mathrm{H}_{2} \mathrm{O}\right)^{-}$or more disordered $\mathrm{Me}(\mathrm{HS})_{2} \mathrm{~S}_{3}{ }^{-}$ complexes. Comparison with results obtained in polysulfide-free solutions (NaHS- $\mathrm{H}_{2} \mathrm{~S}-$ $\mathrm{H}_{2} \mathrm{O}$ ) does not allow separating these species, the XANES spectra obtained in both types of solutions are very similar. To identify these species and to quantify their stability more data are needed.

In conclusions, we have found that in S-rich fluids speciation of both $\mathrm{Cd}$ and $\mathrm{Zn}$ is dominated by S-bearing complexes. Solubility of sphalerite and greenockite increases with $\mathrm{S}$ concentration and attains $10^{-3}$ molality level at 3 mol of S per $\mathrm{kg}$ of fluid. Our new data indicate that these species may be predominant in natural hydrothermal systems at high $\mathrm{S}$ concentrations and thus should be taken into account in the geochemical models. We are now working on better description of these new complexes by using theoretical XANES calculations, solubility and thermodynamic analysis. 

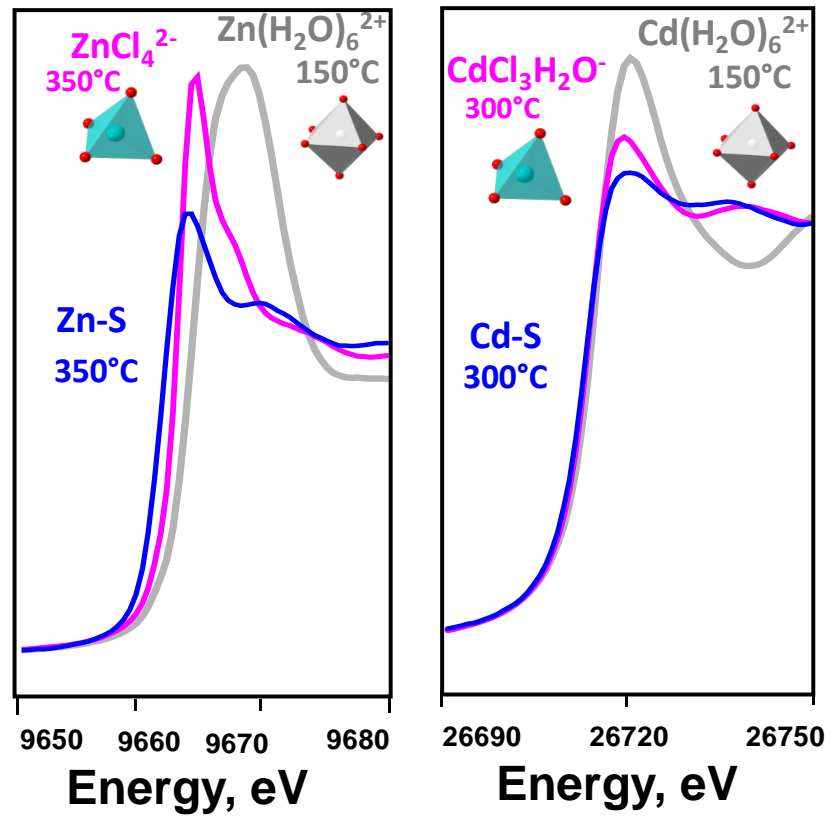

Fig. 1. Experimental XANES spectra of S-bearing complexes of $\mathrm{Zn}$ and $\mathrm{Cd}$ at high T-P in comparison with those of chloride complexes and hydrated ions.
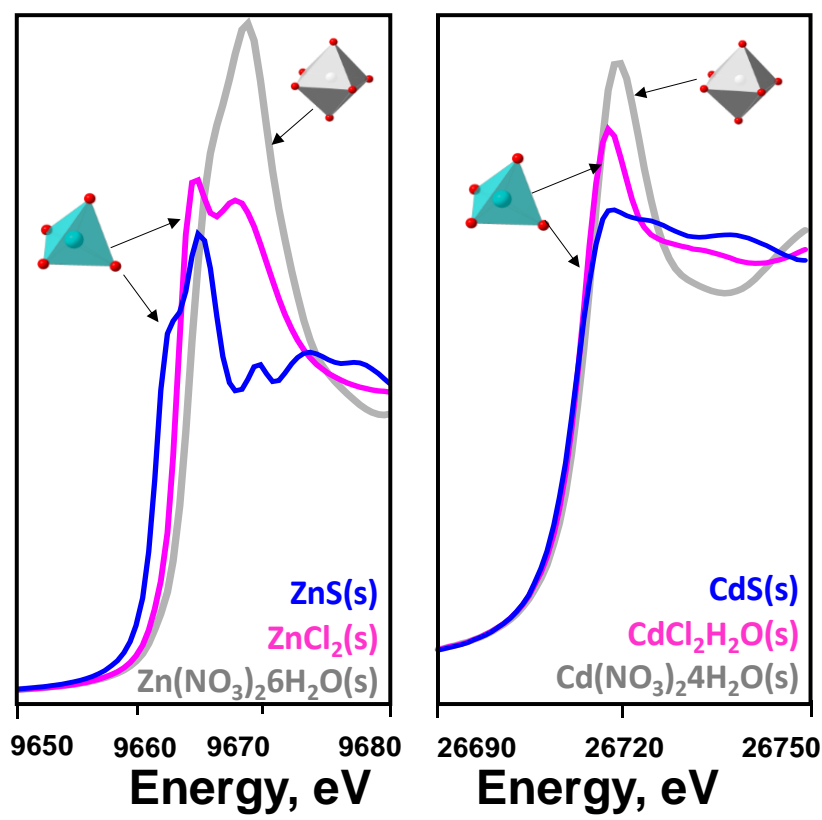

Fig. 2. Experimental XANES spectra of reference compounds of $\mathrm{Zn}$ and $\mathrm{Cd}$ obtained at ambient T-P.

The study was supported by Projet ANR 16-CE31-0017 and the Russian Academy of Sciences basic research project 0136-2018-0021. 


\section{References}

1. E.U. Franck, J. Sol. Chem. 2, 339-356 (1973)

2. J.R. Ruaya, T.M. Seward, Geochim. Cosmochim. Acta 50, 651-662 (1986)

3. G.L. Cygan, J.J. Hemley, W.M. d'Angelo, Geochim. Cosmochim. Acta 58, 4841-4855 (1986)

4. A.V. Plyasunov, I.P. Ivanov, Geochem. Int. 28, 77-90 (1991)

5. A. J. Anderson, R. A. Mayanovic, S. Bajt, Can. Mineral. 33, 499-508 (1995)

6. E.F. Bazarkina, G.S. Pokrovski, A.V. Zotov, J.-L. Hazemann, Chem. Geol. 276, 1-17 (2010)

7. E.F. Bazarkina, A.V. Zotov, N.N. Akinfiev, Geol. Ore Deposits 52, 167-178 (2010)

8. N.N. Akinfiev, B.R. Tagirov, Geochem. Int. 52, 214-232 (2014)

9. B.R. Tagirov, T.M. Seward, Chem. Geol. 269, 301-311 (2010)

10. D. Testemale, R. Argoud, O. Geaymond, J.-L. Hazemann, Rev. Sci. Instrum. 76, 043905-043909 (2005)

11. G.S. Pokrovski, J. Dubessy, Earth Planet. Sci. Lett. 411, 298-309 (2015) 